\title{
Avaliação das propriedades da torta de canola em processo de extração por prensa extrusora automatizada variando a temperatura e a rotação
}

Evaluation of the properties of the canola cake in automated extruder press extraction process by varying temperature and rotation

Evaluación de las propiedades de la torta de canola en proceso de extracción por prensa extrusora automatizada variando la temperatura y la rotación

Hamom Ventura Rodrigues ORCID: https://orcid.org/0000-0002-2604-8120 Universidade Estadual do Oeste do Paraná, Brasil E-mail: hamom.unir.agora@gmail.com

Reginaldo Ferreira Santos ORCID: https://orcid.org/0000-0002-7745-9173 Universidade Estadual do Oeste do Paraná, Brasil E-mail: reginaldo.santos@unioeste.br

Jorge Andrés Retamal Salgado ORCID: https://orcid.org/0000-0002-2867-7801 Universidad Adventista de Chile, Chile E-mail: jorgeretamal@unach.cl

Cristiano Fernando Lewandoski ORCID: https://orcid.org/0000-0001-5944-5723 Universidade Estadual do Oeste do Paraná, Brasil E-mail: cristiano@aceletric.com Bruna de Villa

ORCID: https://orcid.org/0000-0002-2401-7312 Universidade Estadual do Oeste do Paraná, Brasil E-mail: bruna.devilla.58@hotmail.com Luciene Kazue Tokura

ORCID: https://orcid.org/0000-0001-9758-0141 Universidade Estadual do Oeste do Paraná, Brasil E-mail: lucienetokura@gmail.com

Jair Antonio Cruz Siqueira

ORCID: https://orcid.org/0000-0002-8140-444X Universidade Estadual do Oeste do Paraná, Brasil E-mail: jair.siqueira@unioeste.br

Leonardo da Silva Reis

ORCID: https://orcid.org/0000-0002-9239-6158 Universidade Estadual do Oeste do Paraná, Brasil E-mail: leonardoreis183@hotmail.com Benhurt Gongora

ORCID: https://orcid.org/0000-0002-4291-9790 Universidade Estadual do Oeste do Paraná, Brasil E-mail: benhurt.gongora@unioeste.br

Fernando Luiz da Cruz Balena ORCID: https://orcid.org/0000-0002-6029-8166 Universidade Estadual do Oeste do Paraná, Brasil

E-mail: fernandobalena@yahoo.com.br Joyce Bueno Mafra

ORCID: https://orcid.org/0000-0002-9181-1612 Universidade Estadual do Oeste do Paraná, Brasil

E-mail: bueno.mafra@hotmail.com

Ricardo Sonsim de Oliveira

ORCID: https://orcid.org/0000-0003-0390-9212 Instituto Federal do Paraná, Brasil E-mail: ricardo.oliveira@ifpr.edu.br

\section{Resumo}

As culturas oleaginosas apresentam importante destaque no setor agrícola brasileiro, tanto para a produção de alimentos (grãos, óleo e farelos), fármacos e biocombustíveis. Um dos critérios para o aprimorado das tecnologias para 
desenvolver produtos com qualidade superior e valor agregado, tem sido por meio do parâmetro nutricional. Dessa forma, torna-se importante aperfeiçoar o processo de prensagem mecânica contínua de forma a obter o ponto ótimo de temperatura e rotação de extração para disponibilizar maior qualidade nutricional do óleo e da torta de canola. Diante do exposto, foi objetivo do estudo avaliar o processo de prensagem mecânica de grãos de canola em diferentes temperaturas e velocidades de rotação em uma extrusora mecânica com automação sobre as características bromatológicas, cor $(\Delta \mathrm{E})$. Bem como avaliar a umidade de torta, fibra bruta, extrato etéreo, proteína, carboidratos e resíduo mineral fixo. O estudo foi desenvolvido em esquema fatorial $4 \times 5$, sendo 4 temperaturas $(110-120,120-130$, $130-140$ e $\left.140-150{ }^{\circ} \mathrm{C}\right)$ e 5 velocidades $(1000,1200,1400,1600$ e $1800 \mathrm{rpm})$. Foi determinado o coeficiente $\left(\mathrm{R}^{2}\right)$ como um parâmetro estatístico no qual os valores máximos em porcentagem de umidade de torta, fibra bruta, extrato etéreo, proteína, carboidratos e resíduo mineral fixo foram, respectivamente, 9,19; 17,19;32,66; 35,90; 27,29 e 7,32\%. Mediante a cor da torta de canola foi perceptível que a coloração mais escura da torta apresentou alta porcentagem de proteína, e as cores mais claras, alta porcentagem de extrato etéreo.

Palavras-chave: Brassica napus L.; Óleo; Qualidade; Extração mecânica.

\begin{abstract}
Oil crops are important in the Brazilian agricultural sector, both for food production (grains, oil, and bran), pharmaceuticals and biofuels. One of the criteria for the improvement of technologies to develop products with superior quality and added value has been through the nutritional parameter. In this way, it is important to improve the continuous mechanical pressing process in order to obtain the optimum temperature point and extraction rotation to provide higher nutritional quality of the oil and the canola cake. In view of the above, the objective of the study was to evaluate the process of mechanical pressing of canola grains at different temperatures and rotational speeds in a mechanical extruder with automation over bromatological characteristics, color $(\Delta \mathrm{E})$. As well as evaluate pie moisture, raw fiber, ethereal extract, protein, carbohydrates, and fixed mineral residue. The study was developed in factor scheme 45 , being 4 temperatures (110-120, 120-130, 130-140 and 140-150 $\left.{ }^{\circ} \mathrm{C}\right)$ and 5 speeds $(1000,1200,1400,1600$ and $1800 \mathrm{rpm})$. The coefficient $\left(\mathrm{R}^{2}\right)$ was determined as a statistical parameter in which the maximum values in percentage of pie moisture, crude fiber, ethereal extract, protein, carbohydrates, and fixed mineral residue were, respectively, $9.19 ; 17.19 ; 32.66 ; 35.90 ; 27.29$ and $7.32 \%$. By the color of the canola pie, it was noticeable that the darker coloring of the pie presented high percentage of protein, and the lighter colors, high percentage of ethereal extract.
\end{abstract}

Keywords: Brassica napus L.; Oil; Quality; Mechanical extraction.

\title{
Resumen
}

Los cultivos oleaginosos presentan importante destaque en el sector agrícola brasileño, tanto para la producción de alimentos (granos, aceite y salvado), fármacos y biocombustibles. Uno de los criterios para el perfeccionado de las tecnologías para desarrollar productos con calidad superior y valor agregado, ha sido por medio del parámetro nutricional. Por lo tanto, es importante perfeccionar el proceso de prensado mecánico continuo para obtener el punto óptimo de temperatura y rotación de extracción para proporcionar una mayor calidad nutricional del aceite y la torta de canola. Ante lo expuesto, fue objetivo del estudio evaluar el proceso de prensado mecánico de granos de canola en diferentes temperaturas y velocidades de rotación en una extrusora mecánica con automatización sobre las características bromatológicas, color $(\Delta \mathrm{E})$. Así como evaluar la humedad de pastel, fibra cruda, extracto etéreo, proteína, carbohidratos y residuos minerales fijos. El estudio fue desarrollado en esquema factorial 45 , siendo 4 temperaturas $\left(110-120,120-130,130-140\right.$ y $\left.140-150{ }^{\circ} \mathrm{C}\right)$ y 5 velocidades $(1000,1200,1400,1600$ y 1800 rpm). Se determinó el coeficiente $\left(\mathrm{R}^{2}\right)$ como un parámetro estadístico en el cual los valores máximos en porcentaje de humedad de pastel, fibra bruta, extracto etéreo, proteína, carbohidratos y residuo mineral fijo fueron, respectivamente, 9,$19 ; 17,19 ; 32,66 ; 35,90 ; 27,29$ y 7,32\%. Mediante el color del pastel de canola fue perceptible que la coloración más oscura del pastel presentó un alto porcentaje de proteína, y los colores más claros, un alto porcentaje de extracto etéreo. Palabras clave: Brassica napus L.; Aceite; Calidad; Extracción mecánica.

\section{Introdução}

O crescimento populacional é um fator relevante ao longo do tempo na qual, influencia decisivamente a busca por tecnologias de produção e qualidade, e se permite organizar as demandas sociais em termos de segurança alimentar determinadas pelas diretrizes de sustentabilidade (Panizzon, Cenci, Grabowski, \& Jahno, 2020; Ulian, Lima, \& Lemos, 2017).

A modernização dos processos de produção nas atividades agrícolas desempenha fator chave para o desenvolvimento da qualidade da matéria-prima e, portanto, influencia a qualidade do produto final. Assim, as normatizações internacionais com certificações impõem uma atenção especial no que tange a comercialização tanto na importação e exportação dos mesmos (Araújo, 2014). 
A demanda principal para o desenvolvimento da pecuária, importante setor agro, tem como premissa a produção de matéria-prima: rações proteinadas, que sustentam as criações em diversas fazes do seu desenvolvimento, principalmente aves, suínos e bovinos, além de peixes, para o consumo humano.

As rações proteicas são grande parte advindo de culturas oleaginosas, e, portanto, as características dessas culturas influenciam decisivamente o desenvolvimento das criações do setor da pecuária. A qualidade das rações tem seu valor biológico determinado pela presença de aminoácidos essenciais, nos quais, suas proporções podem melhorar ou atrapalhar o desempenho animal (Sarwar Gilani, Wu Xiano, \& Cockell, 2012; Pighinelli, 2010).

Devido à demanda crescente do setor de energia de biomassa e de alimentos, o Brasil passa a ser um ponto chave na exploração de diversas metodologias e tecnologias, para a eficiência de energia nos setores produtivos e no melhoramento do produto final do processo produtivo. Portanto o aperfeiçoamento das rações animais são uma das prioridades dos órgãos privados e particulares deste setor.

Aliando-se, portanto, a alta demanda de rações proteicas e a necessidade da produção de óleo vegetal para consumo e para biocombustíveis entre outras aplicações industriais destacam-se entre diversas culturas vegetais oleaginosas a canola. (Canola Council of Canada, 2011).

Dentre as culturas oleaginosas, a canola (Brassica napus L. var. oleífera) variedade melhorada da colza (Brassica napus L.) se destaca com uma diversidade de características importantes. Seja como alimento funcional ou inserido como parte dos programas governamentais de implantação de culturas energéticas, para o desenvolvimento nacional (De Mori, Tomm, \& Ferreira, 2014).

A cultura de canola é a terceira maior produção mundial, ficando atrás apenas das culturas de soja e de palma em relação a produção mundial de óleo (Rivas, \& Bautista, 2003; Vieira et al., 2010; Haeberlin, Nunes, Medeiros, Jaques, \& Paraginski, 2020).

A Produção estimada pela Associação Brasileira de Óleos Vegetais (ABIOVE), teve avanço no período de 2019 para 2020 de 33,991 milhões de toneladas de farelo e 8,969 milhões de toneladas de óleo, somando a soja e com uma fração da mesma em canola (Abiove, 2019).

A cultura ganha destaque em sistemas de rotação de culturas, como excelente alternativa para o inverno no sul do Brasil. (Rigon et al., 2017; Milla et al., 2020). Em 2017, foram cultivados no Brasil 43 mil hectares de canola, rendendo em média 1569 $\mathrm{kg} \mathrm{ha}^{-1}$, produzindo um total de 71,9 mil toneladas de cereais. Dentre os estados produtores, o Rio Grande do Sul se destacou, com 90,4\% de participação na produção nacional, seguido pelo Paraná com 9,6\% (Conab, 2017).

Alguns critérios são imprescindíveis para a gestão da produção agrícola no país, levando em consideração o aspecto logístico e econômico, entre os quais, a aclimatação das culturas, para áreas de plantio, o padrão de produção, a qualidade e a produtividade, mediante a estes critérios a canola tem se destacado das demais culturas no quesito culturas de inverno (Hoffmann \& Kageyama, 1985).

No Brasil os padrões de qualidade de alimentos industrializados são regulamentados por normatizações de qualidade, tais como, Ministério da Saúde, Agência Nacional de Vigilância Sanitária (Anvisa), assim como, o Serviço de Inspeção Federal (SIF).

A canola é uma das principais fontes de óleo vegetal comestível, além de ser uma fonte rica em ácidos graxos insaturados (ácido oleico, ácido linoleico e alfa-linoleico) e, pobres em ácidos graxos saturados, suas propriedades permanecem no farelo devido a porcentagem de óleo não extraído pelos processos físicos e químicos (Tomm, Wiethölter, Dalmago, \& Santos, 2009).

Para Neves, Cenci e Rodrigues (2016) alguns fatores podem influenciar a qualidade nutricional da torta e do óleo, provenientes das extrações das sementes das oleaginosas. Dentre esses fatores estão: variação na qualidade nutritiva da torta 
devido as cultivares, condições agronômicas, método de extração do óleo, temperatura e umidade, durante a extração do óleo e subsequente processamento.

As características da biomassa estão relacionadas ao processamento e a matéria prima, e, portanto, a automação de prensas mecânicas induz um controle sobre as propriedades físico-químicas, quali-quantitativas do farelo e do óleo (Pighinelli, 2010; Bueno et al., 2019).

Piggnelli (2010) afirma ainda que, grande parte da produção industrial de rações e óleo vegetal é baseada inicialmente na prensagem e extração mecânica, na qual é um dos métodos mais amplamente usados para a remoção de óleo de sementes oleaginosas e processamentos das raçoes ou torta em modo contínuo.

Segundo Yacu (1990) o rendimento nutricional envolve os processos de extração e refino no qual envolvem temperatura e rotação e divergem em vários aspectos mediante as diversas características de cada cultura vegetal, mediante aos ajustes dos processos mecânicos e geométricos das prensas extrusoras.

A elevação da temperatura se relaciona com as características da torta, tornando-a mais coesa e facilitando a extração do óleo, entretanto, o controle do mesmo tende a um limite, no qual os efeitos deletérios podem alterar a qualidade física e química do óleo e a bromatologia da torta (Pighinelli, 2010).

Portanto, compreender as limitações da temperatura e rotação, no que tange as propriedades nutricionais são importantes, diante da demanda contínua por eficiência nos processos produtivos, no qual, demandam um maior aproveitamento da matéria prima. Devido a essas demandas, a automação de prensas extrusoras é um importante propulsor para as transformações sociais rurais a nível regional e nacional.

A eficiência dos processos de extração de óleo de culturas oleaginosas, passam pelas modificações incrementais as prensas extrusoras, que segundo Yacu (1990), toda a geometria e velocidade das roscas no controle dos parâmetros de extrusão define as características dos produtos, tais como: grau de cozimento, expansão, densidade, formato, tamanho, aparência, textura, sabor, aroma, cor e umidade final e, consequentemente, o valor final do produto e aceitabilidade.

Portanto, o valor agregado da matéria prima e seus coprodutos têm como consequência os processos de extração que em grande parte são mensurados pela qualidade e quantidade de subprodutos mediante a análises físico-químicas e bromatológicas, por diversas metodologias, como as normatizações consolidadas do Instituto Adolfo Lutz (Instituto Adolfo Lutz, 2008).

Os grãos de canola produzidos no Brasil contem cerca de $25 \%$ de proteínas e $38 \%$ de óleo, com variedades em outros países, chegando a 50\% de óleo (Embrapa, 1991). Além do óleo utilizado na produção de biodiesel, se extrai o farelo, sendo excelente suplemento proteico na produção de ração para animais (Tomm, 2005).

As variações geométricas de prensas extrusoras podem ser automatizadas para busca de uma maior qualidade ou rendimento de prensagem de grãos (Yacu, 1990). Outras variáveis como rotação e temperatura, influenciam o rendimento de óleo e outras características físico-químicas e bromatológicas, como observado nos estudos de Tomm et al. (2009); Scapinello, Furlan, Moreira e Murakami (1996) e Araújo, Andrade, Nolasco, Castro e Castro Neto (2020).

Portanto, o ponto ótimo dos coprodutos pode ser analisado e programado, para automatização eficiência e segurança nutricional.

Assim, por meio da importância ressaltada acima desta cultura, o objetivo deste estudo foi avaliar o processo de prensagem mecânica de grãos de canola em diferentes temperaturas e velocidades de rotação em uma extrusora mecânica com automação, para avaliação das características físico-químicas da torta de canola. 


\section{Metodologia}

O estudo foi conduzido nos laboratórios do Centro de Desenvolvimento de Difusão Tecnológico de Energia Renovável (CDTER) e da Universidade Estadual do Oeste do Paraná (Unioeste), em parceria com a Fundação para o Desenvolvimento Científico e Tecnológico (Fundetec), Cascavel - PR, Brasil ano de 2020.

As sementes de canola (Brassica napus L.) hibrído Hyola 401, utilizadas no experimento foram gentilmente cedidas pela Unioeste, campus de Cascavel, em parceria com o Instituto Agronômico do Paraná (Iapar) de Santa Tereza do Oeste.

A obtenção do óleo e da torta (farelo) ocorreu por meio de uma prensa extrusora Z1500 de fabricação da empresa Zaamp, com alimentação geral em $220 \mathrm{~V}$ trifásico, com um motor de 0,5 CV para alimentação dos grãos SEW e o motor principal de 7,5 CV SEW, com rotação máxima de 1800 rpm. Com tecnologia de automação 4.0 (Figura 1).

Figura 1. Extrusora Zaamp Z1500.

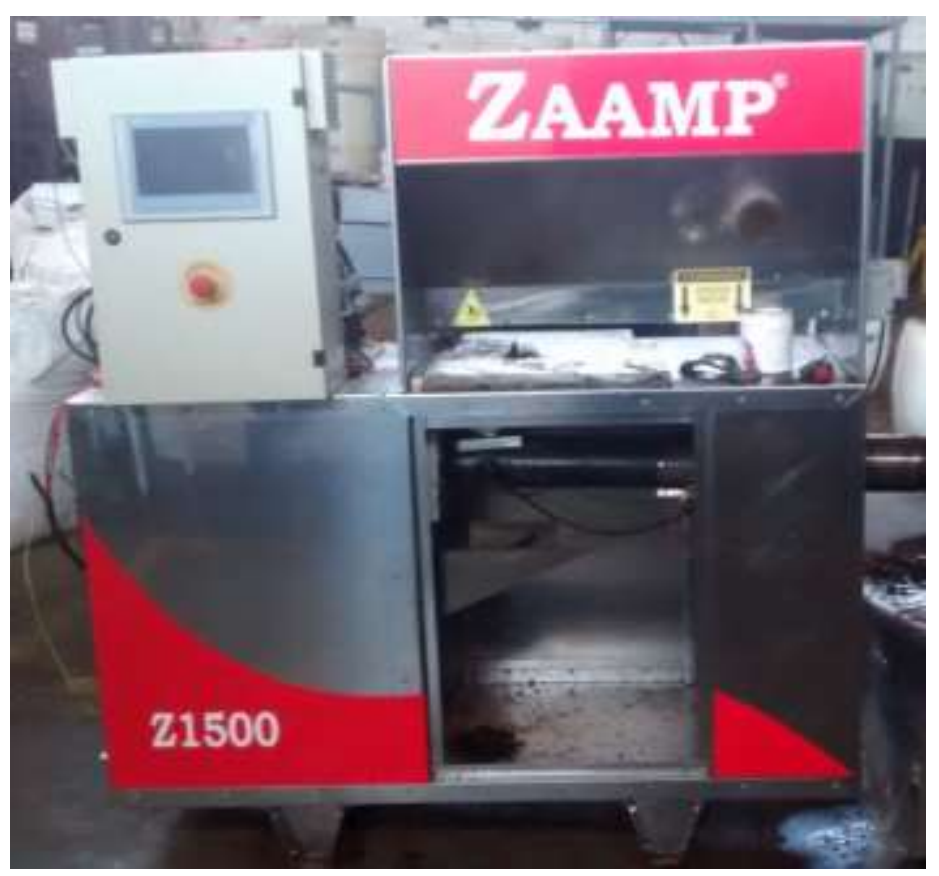

Fonte: Autores.

O processo de extração do óleo consistiu em ligar a prensa, aquecê-la até a faixa de temperatura desejada, definir a velocidade de rotação e colocar as amostras para avaliação.

O delineamento experimental foi fatorial completo com análise de superfície organizado de forma fatorial $4 \times 5$. Para $\mathrm{o}$ presente estudo foram definidas quatro temperaturas (fator 1) nas faixas do intervalo $\left(110-120^{\circ} \mathrm{C}, 120-30{ }^{\circ} \mathrm{C}, 130-140{ }^{\circ} \mathrm{Ce} 140\right.$ $150{ }^{\circ} \mathrm{C}$ ) e cinco velocidades (fator 2) [1000, 1200, 1400, 1600 e 1800 rpm (Rotações por minuto)], para determinação dos efeitos desses parâmetros na prensagem das sementes de canola.

Antes de qualquer processo prático referente à prensagem, foi realizada a análise do local em que estava instalada a prensa, incluindo umidade e temperatura ambiente, juntamente com a data em que estava sendo conduzida a atividade e horário de realização das análises.

A máquina foi ligada e aquecida até a primeira faixa de temperatura, $110-120^{\circ} \mathrm{C}$, e a rotação foi definida, num primeiro momento, para $1000 \mathrm{rpm}$. A amostra de $5 \mathrm{~kg}$ de sementes foi então colocada na adução da máquina e ocorreu a prensagem na zona termomecânica. 
O óleo e a torta foram retirados da máquina, inseridos em recipientes etiquetados e reservados para realização dos ensaios. $\mathrm{O}$ farelo foi homogeneizado em cada experimento antes do processo de análise.

Este processo foi repetido para todos os parâmetros por quatro vezes, para minimização de eventuais erros e discrepâncias nas análises estatísticas, para que fosse possível analisar os dados, a fim de verificar a influência da temperatura e da velocidade da prensa na extração do óleo, em sua qualidade.

\subsection{Parâmetros avaliados na torta de canola}

As análises basearam-se na metodologia proposta pelo Instituto Adolfo Lutz (2008).

\section{Fibra bruta (FB\%)}

A torta homogeneizada foi pesada em balança de precisão com 2,00 gramas da amostra e procedeu-se a extração contínua, pelo extrator Soxhlet, utilizando éter como solvente. Em seguida, foi filtrado e aquecido em estufa, seguido da pesagem e repetição das operações de aquecimento e resfriamento até peso constante, conforme a Equação 1.

$$
\mathrm{CF} \%=(100 . \mathrm{N}) / \mathrm{P}
$$

Onde:

$\mathrm{N}$ : número de gramas na fibra;

P: número de gramas na amostra.

\section{Extrato Etério (EE\%)}

Com o peso de 5,00 g da amostra, a mesma foi colocada em papel filtro e fixou-se utilizando fio de lã prédesengordurado. $\mathrm{O}$ aquecimento por Soxhlet foi mantido e a extração foi continuada durante 8:00 h. Foi então colocado em um extrator por aquecimento para a retirada do hexano do óleo, representado pela Equação 2.

$$
\mathrm{L} \%=(100 . \mathrm{N}) / \mathrm{P}
$$

Onde:

N: número de gramas nos lipídios;

P: o número de gramas na amostra.

\section{Proteína (P\%)}

A matéria orgânica foi decomposta e o nitrogênio existente foi transformado em amônia. Como o teor de nitrogênio das diferentes proteínas foi de aproximadamente $16 \%$, o fator empírico 6,25 foi introduzido para transformar o número de gramas do nitrogênio encontrado no número de gramas das proteínas, como representado pela Equação 3.

$$
\mathrm{P} \%=(\mathrm{V} \cdot 0.14 . \mathrm{f}) / \mathrm{P}
$$


Onde:

V: diferença entre o mL 0,05 M ácido sulfúrico e o número de ml do 0,1 M hidróxido de sódio gasto na titulação;

P: número de gramas na amostra;

f: fator de conversão $(6,25)$.

\section{Amido/Carboidratos (A\%)}

Foi utilizado a verificação da porcentagem de carboidrato por diferença, na qual as somas das porcentagens das massas de Fibra, Umidade, Lipídios, Cinzas e Proteína subtraindo de 100\%, conforme demonstrado pela Equação 4.

$$
\text { Carboidrato } \%=\mathrm{P} \%+\mathrm{F} \%+\mathrm{U} \%+\mathrm{L} \%+\mathrm{C} \%-100 \%
$$

Onde:

F: porcentagem de fibras na amostra;

$\mathrm{U}$ : porcentagem de Umidade na amostra;

L: porcentagem de Lipídios na amostra;

P: porcentagem de Proteína na amostra;

C: porcentagem de Cinzas na amostra;

\section{Cinza - Resíduo Mineral Fixo (CZ\%)}

O procedimento descrito pelo Instituto Adolfo Lutz (2008) consistiu em pesar 5,00-10,00 g da amostra em uma cápsula pré-aquecida, depois secar em estufa onde as cinzas eram brancas ou levemente acinzentadas, conforme a Equação 5.

$$
\mathrm{CZ}=(\mathrm{N} .100) / \mathrm{P}
$$

Onde:

N: número de gramas nas cinzas;

P: número de gramas na amostra.

\section{Umidade da Torta (M\%)}

Aproximadamente 5 gramas da amostra de sementes de canola foram colocados para análise na placa de pesagem. A placa foi fechada com a tampa e pesada em uma escala de precisão de até um miligrama. A placa e a tampa (com a tampa removida) foram colocadas em um forno com circulação e renovação de ar (modelo MA 035-Marconi) previamente mantido a $105 \pm 2{ }^{\circ} \mathrm{C}$ por 3 horas. Este conjunto foi colocado em dessecador até a temperatura ambiente, conforme procedimento descrito pelo Instituto Adolfo Lutz (2008) (Equação 6).

$$
\mathrm{M}(\%)=(100 . \mathrm{N}) / \mathrm{P}
$$

Onde:

M (\%): Umidade;

$\mathrm{N}$ : número de gramas na umidade (perda de massa em g);

$\mathrm{P}$ : número de gramas na amostra. 


\section{Determinação da cor $(\Delta \mathbf{E})$}

Método colorimétrico na qual a cor foi determinada por leitura direta nas amostras, em colorímetro portátil Konica Minouta CR400 CR-400/410. O aparelho foi calibrado em placa cerâmica branca de acordo com padrões pré-estabelecidos pelo fabricante $(\mathrm{Y}=84,5 ; \mathrm{x}=0,3195 ; \mathrm{y}=0,3341)$. As análises em cada amostra foram realizadas com triplicata, obtendo-se valores médios e desvio padrão dos parâmetros da Luminosidade (L*) (Equações 7 e 8).

$$
\begin{aligned}
& \Delta \mathrm{L}=\text { Média de } \mathrm{L}^{*} \text { da triplicata } \\
& \Delta \mathrm{E}=\sqrt{ }\left(\Delta \mathrm{L}^{2}+\Delta \mathrm{a}^{2}+\Delta \mathrm{b}^{2}\right)
\end{aligned}
$$

Onde:

$\mathrm{L}^{*}=$ Luminosidade,

$\mathrm{a}^{*}=$ coordenada vermelho/verde (+a indica vermelho e $-\mathrm{a}$ indica verde),

$\mathrm{b}^{*}=$ coordenada amarelo / azul (+b indica amarelo e $-\mathrm{b}$ indica azul)

\section{Granulometria}

A determinação da granulometria foi realizada utilizando as peneiras granulométricas Bertal (Figura 2) com abertura de $900 \mathrm{~mm} / \mu \mathrm{m}, 1200 \mathrm{~mm} / \mu \mathrm{m}$, e $1800 \mathrm{~mm} / \mu \mathrm{m}$.

Figura 2. Peneiras granulométricas para extração do farelo e torta de canola em relação a variação da temperatura e rotação.

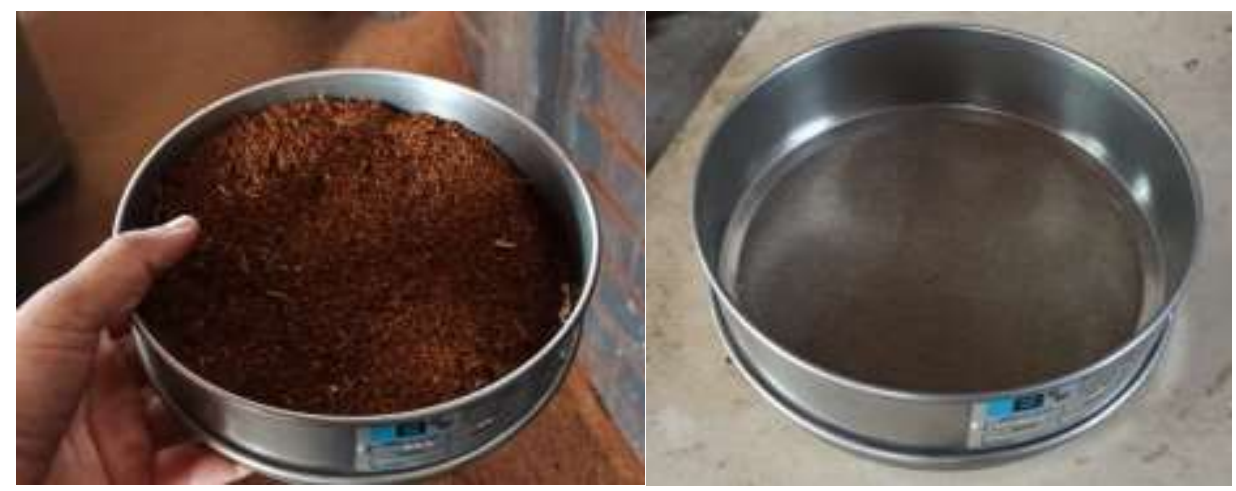

Fonte: Autores.

\subsection{Análise estatística}

Após a coleta dos dados das amostras de torta e óleo bruto da semente de canola foi realizada a análise de variância fator único (Anova) pelo software Excel (Office 2016 ${ }^{\circledR}$ ).

O software estatístico Sisvar 5.6 foi utilizado para realizar o teste de Tukey e de regressão. Com o software estatístico Chemoface, por fatorial completo se obteve a metodologia da superfície de resposta (RSM), com os resultados obtidos da análise de variância, calcularam-se os efeitos principais e a relação entre rotação e temperatura determinando quais os efeitos mais significativos para o processo em estudo e comparando-os com o valor do efeito e o erro experimental estimado utilizando o valor - p de significância com $95 \%$ de confiabilidade.

\section{Resultados e Discussão}

Mediante a inúmeras análises para a determinação da qualidade da torta baseado em suas propriedades bromatológicas 
foi possível observar que a menor rotação teve uma coloração mais clara do que as demais rotações, levando em consideração a temperatura. Devido a diversidade de interações as colorações não tiveram um padrão específico visual tendendo do escuro preto ao marrom claro (Tabela 1).

Tabela 1. Análise visual da torta de canola obtida em diferentes rotações e temperaturas

\begin{tabular}{|c|c|c|c|c|}
\hline TEMPERATURA & $110-120$ & $120-130$ & $130-140$ & $140-150$ \\
\hline ROTAÇĀO (RPM) & & & & \\
\hline 1000 & & & & \\
\hline 1200 & & & & \\
\hline 1400 & & & & \\
\hline 1600 & & & & \\
\hline 1800 & & & & \\
\hline
\end{tabular}

Fonte: Autores.

Na Tabela 1 observam-se as amostras para análise onde foi possível verificar as várias tonalidades de vermelho e cinza, de acordo com as variações de velocidade e temperatura. As amostras de torta de canola tiveram uma tendência a terem uma tonalidade vermelho claro, através da análise colorimétrica, conforme o aumento da temperatura e a rotação, pois, acelera os processos metabólicos de degradação dos pigmentos, estrutura do suprimento nutricional, revestimento protetor e o tecido nutritivo.

Devido a diversas interações como quantidade de óleo na torta e ineficiência do sistema em retirar uma porcentagem maior de óleo da torta, foi necessário o uso de outro método colorimétrico para fazer a análise e classificação precisa para a análise da cor da torta de canola.

Os valores de $\Delta \mathrm{E}$ (diferença de cor) foram calculados levando em consideração a semente in natura. Portanto, mediante a Tabela 2 demonstrou informações importantes quanto a cor.

Tabela 2. Diferença de cor para torta de canola em termos de $\Delta \mathrm{E}$ e desvio padrão para extração em diferentes temperaturas e velocidades de rotação.

\begin{tabular}{ccccc}
\hline \multirow{2}{*}{ Rotação (rpm) } & \multicolumn{4}{c}{ Temperatura $\left({ }^{\circ} \mathrm{C}\right)$} \\
\cline { 2 - 5 } & $110-120$ & $120-130$ & $130-140$ & $140-150$ \\
\hline 1000 & 12,44 & 16,37 & 18,39 & 13,39 \\
1200 & 12,09 & 15,38 & 15,69 & 16,77 \\
1400 & 15,31 & 17,40 & 14,92 & 15,06 \\
1600 & 16,06 & 12,98 & 16,07 & 12,39 \\
1800 & 16,00 & 17,54 & 17,98 & 15,13 \\
\hline Desvio Padrão & 1,95 & 1,86 & 1,50 & 1,69 \\
\hline & & Fonte: Autores.
\end{tabular}

$\mathrm{Na}$ torta de canola os valores de $\Delta \mathrm{E}$, permearam a faixa de 12-18, conforme a Tabela 2 , o que leva a uma tendência da torta à coloração avermelhada. O desvio padrão apresentado para as faixas de temperatura não tiveram uma dispersão grande e, portanto, o agrupamento dos valores em termos de $\Delta \mathrm{E}$, não apresentou grande variação dos mesmos. 
Foi possível classificar cada faixa de temperatura como referenciais de $\Delta \mathrm{E}$. O maior valor para a torta correspondeu a 17,98, no qual, demonstrou, uma cor mais clara, para o vermelho, ou seja, correspondeu na amostra de temperatura na faixa de 130-140 ${ }^{\circ} \mathrm{C}$ e de rotação de $1800 \mathrm{rpm}$ no processo de extração, indicando menor presença de óleo no farelo.

O menor valor correspondeu a 12,09, no qual, demonstrou uma cor mais escura para a torta, tendendo ser escura na temperatura da faixa de $110-120{ }^{\circ} \mathrm{C}$ e de rotação de $1200 \mathrm{rpm}$ no processo de extração e, portanto, percebeu-se uma presença maior de óleo na torta ou uma torrefação que demostrou a cor escura.

A classificação estatística dessa variação foi perceptível no boxplot, na qual, foi possível compreender a dinâmica e variação da temperatura e rotação na torta, em relação ao $\Delta \mathrm{E}$, demonstrado na Figura 3.

Figura 3. Boxplot das médias em função de $\Delta \mathrm{E}$ (diferença de cor) da variação da temperatura e rotação.

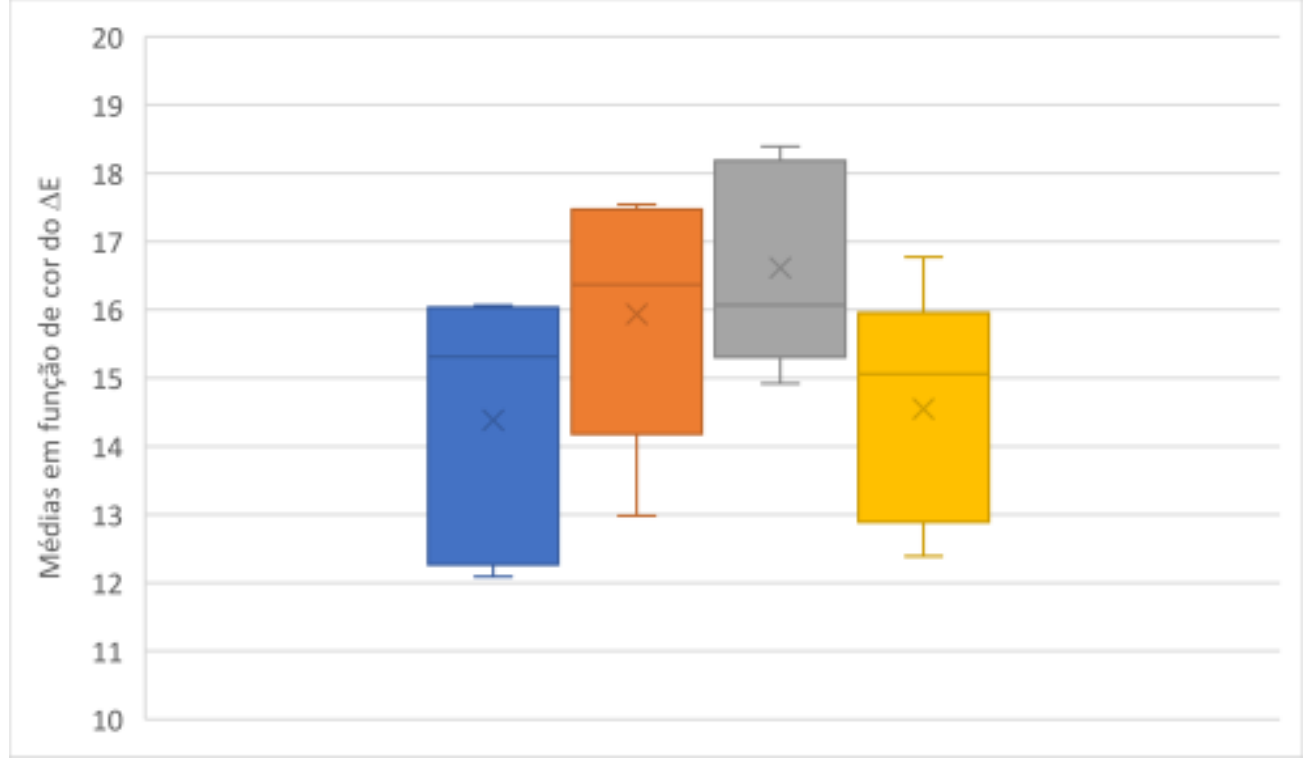

Fonte: Autores.

Portanto, o comportamento colorimétrico levando em consideração a média da diferença de cor $(\Delta \mathrm{E})$ demonstrou a maior variabilidade dos valores pelas amostras na menor faixa de temperatura $\left(110-120^{\circ} \mathrm{C}\right)$, onde foi possível compreender a partir dos mesmos que, os maiores desvio padrão $(\sigma=2,03)$ e coeficiente de variação $(C V=14,20 \%)$, permaneceram aceitáveis mediante a análise estatística. E, portanto, o menor desvio padrão $(\sigma=1,70)$ e coeficiente de variação $(C V=11,67 \%)$ permaneceu na maior faixa de temperatura de $140-150{ }^{\circ} \mathrm{C}$.

Mediante o fatorial completo, a superfície de resposta e o ponto para otimização da umidade na torta de canola podem ser observadas na Figura 4. Na qual se representou o modelo em 2D e 3D representando visualmente os pontos máximos e mínimos da umidade em relação a temperatura e rotação. 
Figura 4. Gráfico de Superfície de umidade da torta de canola em relação a variação da temperatura e rotação.
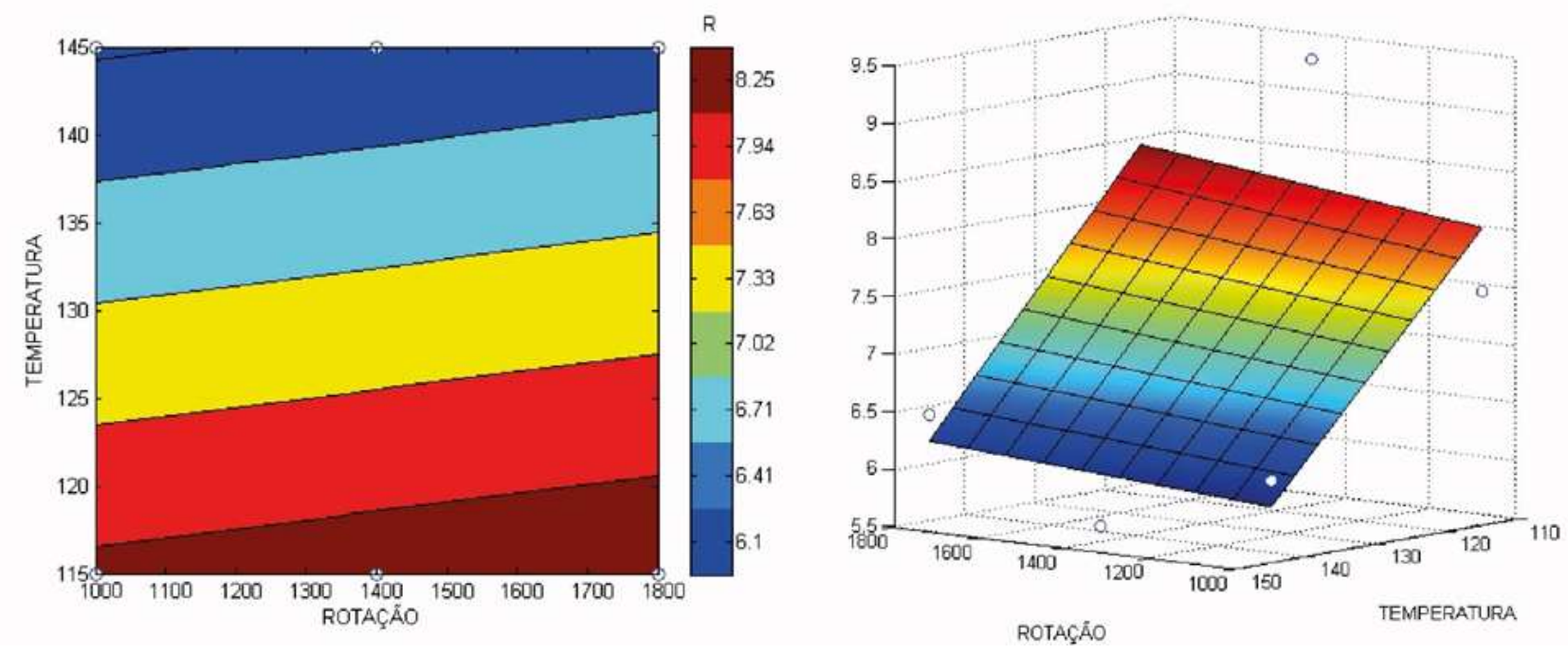

Fonte: Autores.

O coeficiente de variação de 17,30\%, com média geral de 5,68 para 60 observações, esteve abaixo de 20\%, o que tornou os dados estáveis e com confiabilidade. Foi possível observar que as menores temperaturas e rotações tiveram a menor porcentagem de umidade, enquanto, a maior rotação e maior temperatura se tornou inversamente proporcional.

Percebeu-se que as rotações de 1600 e $1400 \mathrm{rpm}$ tiveram as mais altas porcentagens de umidade quando estiveram sobre baixas temperaturas.

Na Figura 5, observou-se o comportamento de carboidrato em porcentagem nos gráficos 2D e 3D, nos quais demonstraram que os gráficos apresentaram uma tendência inversamente proporcional, no qual, o aumento da temperatura e rotação diminuía expressivamente de forma qualitativa a porcentagem de carboidrato na torta de canola.

Figura 5. Comportamento variável em $2 \mathrm{D}$ e 3D do carboidrato em função das variáveis temperaturas e rotação para torta de canola.
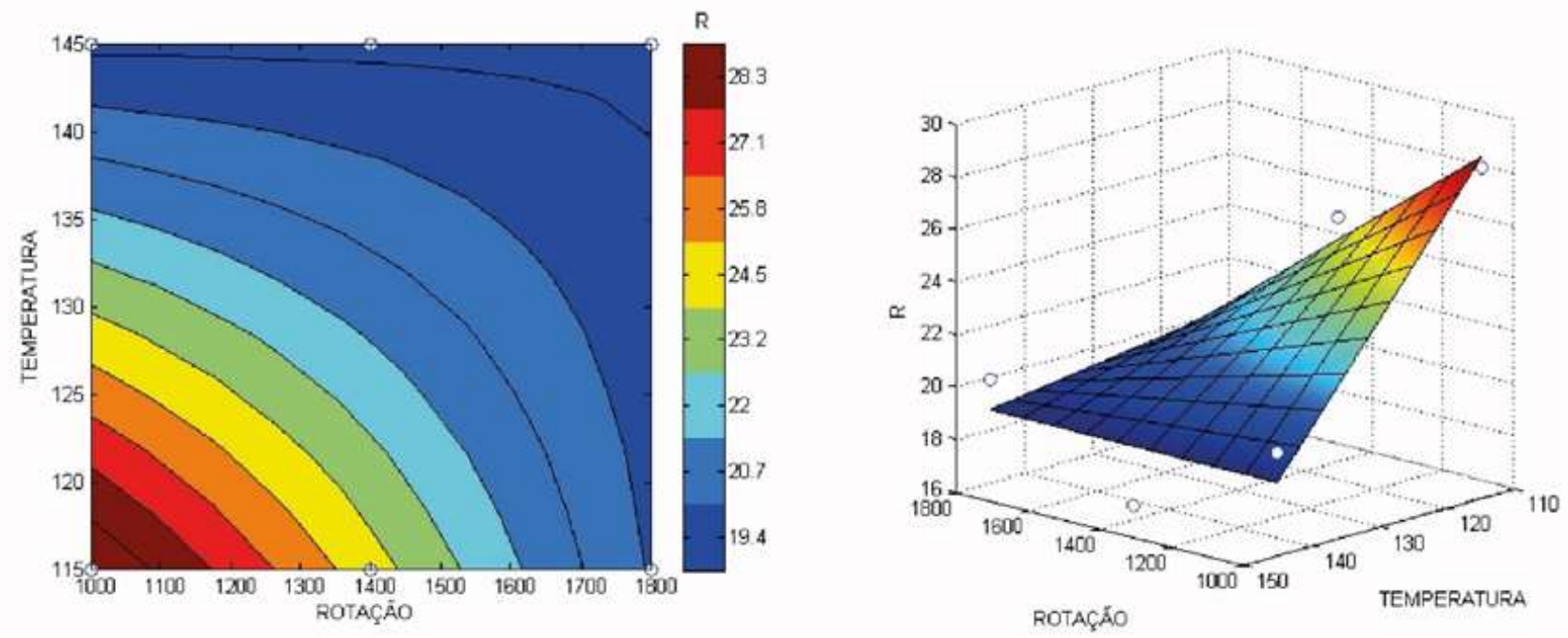

Fonte: Autores. 
O coeficiente de variação do carboidrato (18,18\%), com média geral de 20,50 para 60 observações, ficou abaixo de $20 \%$ o que tornou os dados estáveis e com confiabilidade. Para Barthet e Daun (2011) e Newkirk (2011), o carboidrato presente em grãos de canola pode alterar dependendo da variedade das sementes, condições climáticas e agronômicas, além da forma de processamento dos mesmos.

Na Figura 6, pode ser observado o comportamento variável em 2D e 3D de proteína em função das variáveis temperaturas e rotação para torta de canola.

Figura 6. Comportamento variável em 2D e 3D de proteína em função das variáveis temperaturas e rotação para torta de canola.
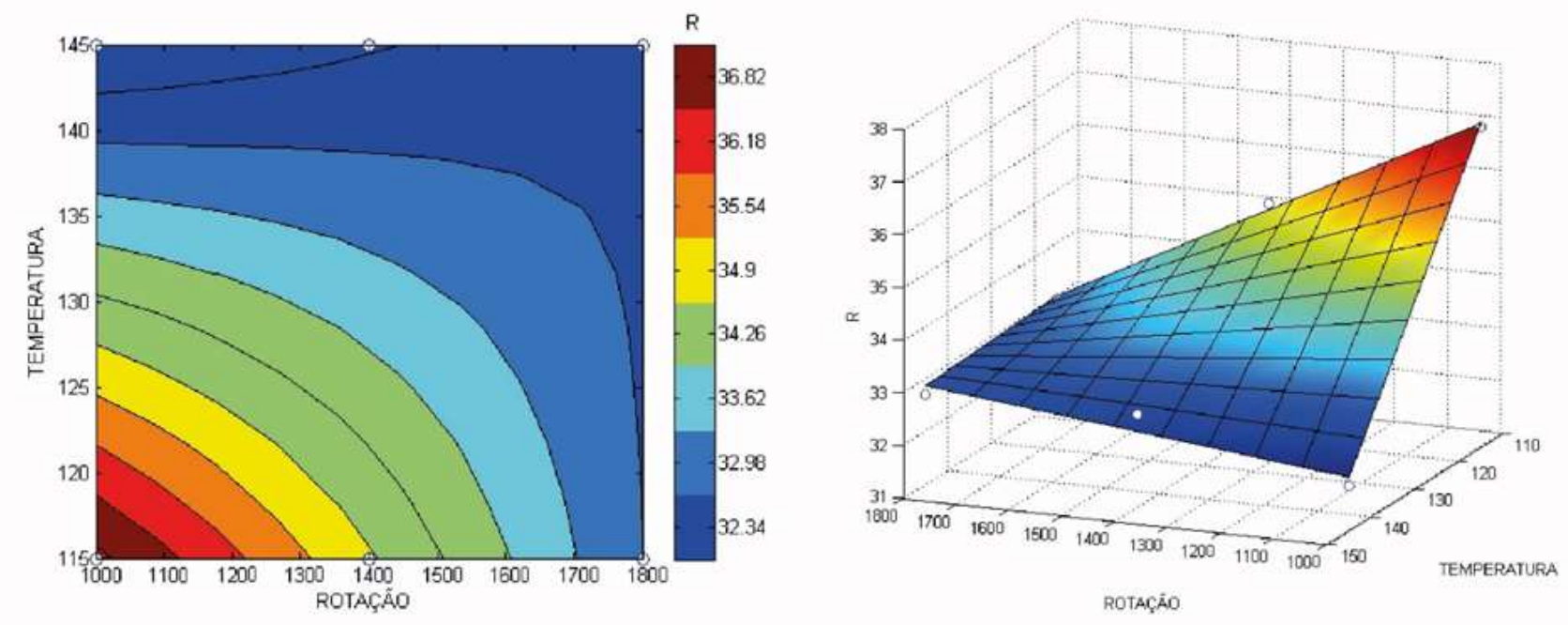

Fonte: Autores.

O coeficiente de variação da proteína (5,12\%), apresentou média geral de 32,50 para 60 observações e, portanto, os valores em porcentagem de proteína da torta de canola apresentaram valores mínimo de 29,04\% para a rotação de 1600 e na faixa de temperatura de $110-120^{\circ} \mathrm{C}$. E valores máximos de $37,08 \%$, para a rotação de $1000 \mathrm{rpm}$, na faixa de temperatura de 110 $120{ }^{\circ} \mathrm{C}$.

Na Figura 7 pode ser observado o comportamento variável em 2D e 3D de fibras em função das variáveis temperaturas e rotação para torta de canola.

Figura 7. Comportamento variável em 2D e 3D de fibra em função das variáveis temperaturas e rotação para torta de canola.
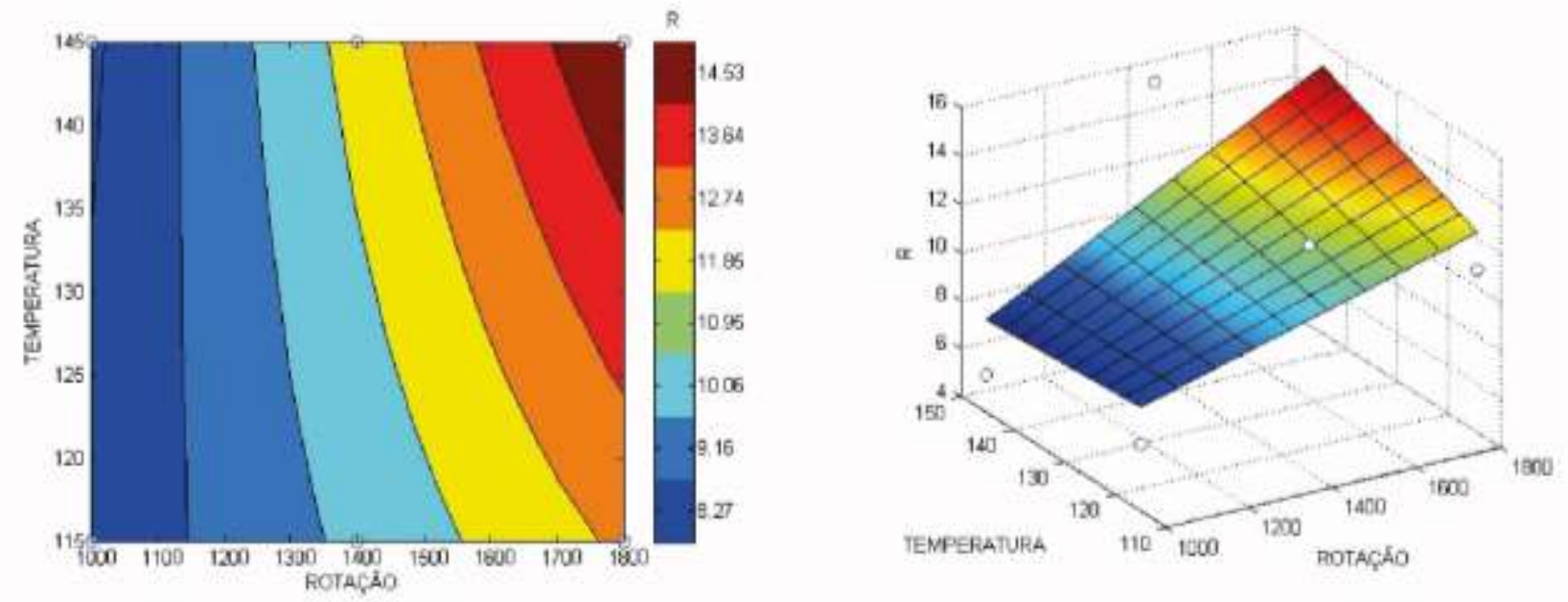
Na Figura 7, os gráficos apresentaram uma tendência inversamente proporcional, no qual, com o aumento da temperatura e rotação diminuam expressivamente de forma qualitativa, a porcentagem de carboidrato na torta de canola.

Os maiores valores de fibras foram encontrados nas mais altas rotações e maiores temperaturas $\left(140-150{ }^{\circ} \mathrm{C}\right.$ e 1800 $\mathrm{rpm})$, e proporcionalmente os menores valores de fibra, se encontraram nas mais baixas rotações e temperaturas $\left(110-120^{\circ} \mathrm{C}\right.$ e $1000 \mathrm{rpm})$.

Por meio da Figura 8, pode ser observado o comportamento de extrato etéreo em superfícies, nos gráficos 2D e 3D. Observou-se que o gráfico apresentou uma tendência a ser diretamente proporcional a temperatura, onde com o aumento da temperatura, aumentou-se expressivamente a porcentagem de extrato etéreo na torta. Enquanto, a rotação foi inversamente proporcional ao aumento da rotação, e diminuiu expressivamente a porcentagem de extrato etéreo na torta de canola.

Figura 8. Comportamento variável Temperatura x rotação em 2D e 3D de extrato etéreo em função das variáveis temperaturas e rotação para torta de canola.
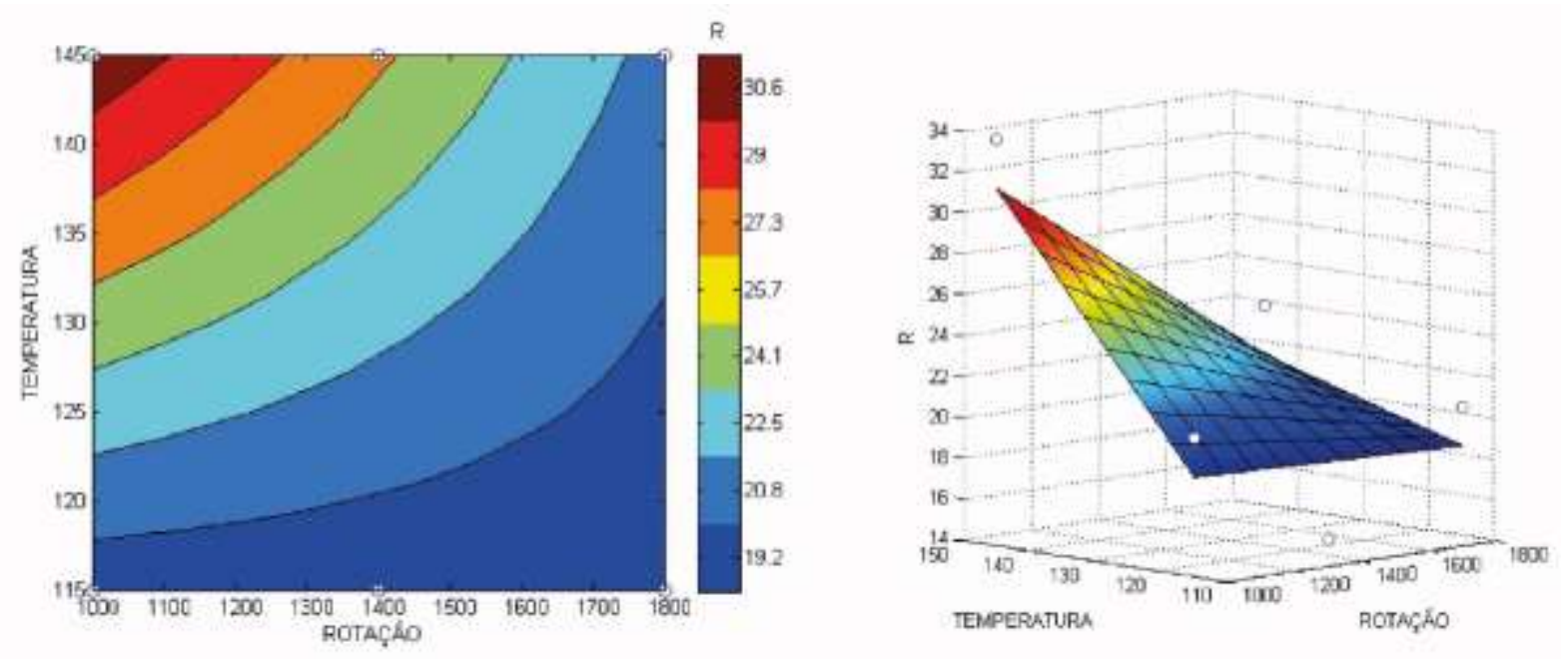

Fonte: Autores.

Na Figura 9 pode ser observado o comportamento de resíduo mineral fixo em porcentagem. Nas superfícies dos gráficos 2D e 3D, observou-se que, o gráfico apresentou uma tendência inversamente proporcional a rotação e diretamente proporcional a temperatura, em que, o aumento da temperatura, diminuiu expressivamente a porcentagem de resíduo mineral fixo. Enquanto, o aumento da rotação, aumentou a quantidade expressivamente de resíduo mineral fixo, na torta de canola. 
Figura 9. Comportamento variável resíduo mineral fixo em 2D e 3D do resíduo mineral fixo em função das variáveis temperaturas e rotação para torta de canola.
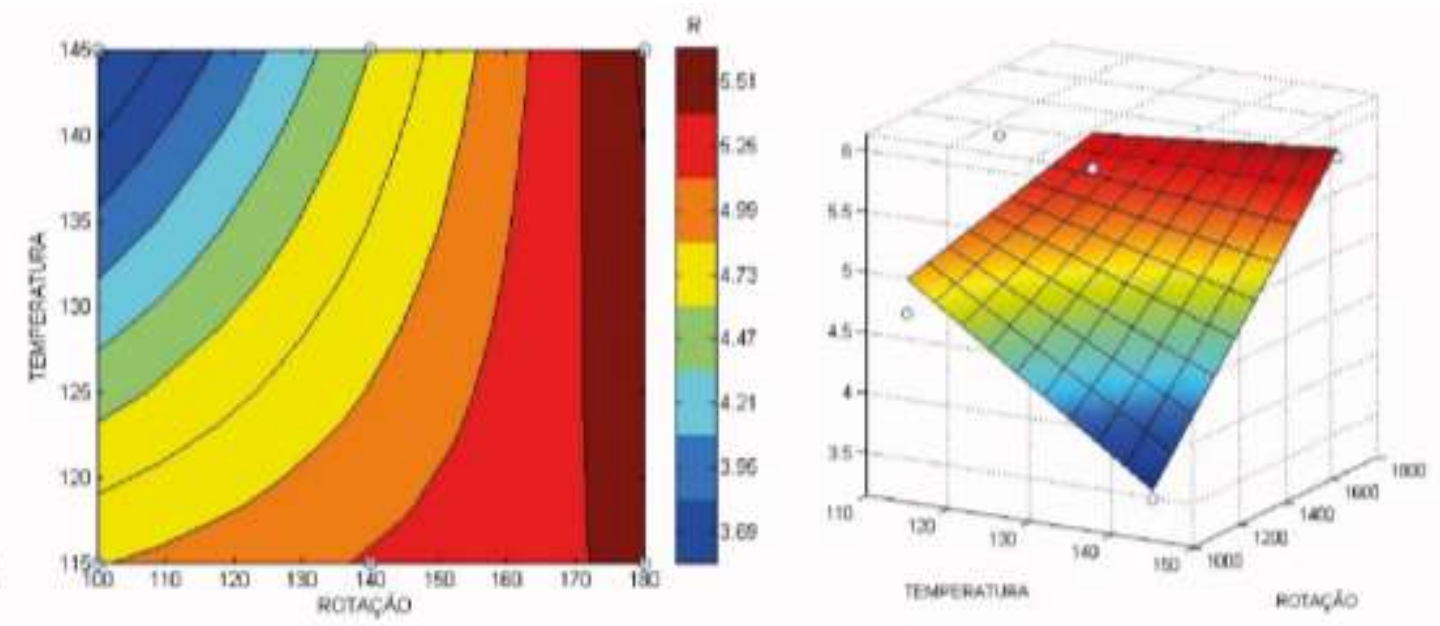

Fonte: Autores.

A quantidade de resíduo mineral fixo, encontrada na torta em função da variação de temperatura e rotação também correspondeu a faixa de valores encontradas no trabalho de Bertol e Zanotto (1997), que foi de 5,14\%.

No conjunto de operações necessárias para se obter o máximo potencial nutricional de um alimento, deve-se verificar também a granulometria e, portanto, o tamanho do grão/farelo na sua fase final. Uma vez que, esse parâmetro apresentou um aspecto importante ao dimensionamento dos processos para a eficiência da máquina extrusora.

Mediante a análise do comportamento da granulometria da torna foi possível classifica-las, de acordo com as peneiras utilizadas (Figura 10), no qual, nas rotações de 1200 e $1400 \mathrm{rpm}$, com a temperatura de $110-120^{\circ} \mathrm{C}$ ocorreram paradas por causa do embuchamento. O mesmo, ocorrendo na amostra com $1800 \mathrm{rpm}$ e temperatura de $130-140{ }^{\circ} \mathrm{C}$. Também foi possível observar que as menores granulometrias ocorreram nas rotações de 1200 e $1400 \mathrm{rpm}$, e nas temperaturas mais elevadas, entre $120-150{ }^{\circ} \mathrm{C}$.

Figura 10. Análise de granulometria de diversas aberturas para torta de canola em relação a variação da temperatura e rotação a partir das modas estatísticas. $1: 110-120{ }^{\circ} \mathrm{C} ; 2$ : $120-130{ }^{\circ} \mathrm{C} ; 3: 130-140{ }^{\circ} \mathrm{C}$ e $4: 140-150{ }^{\circ} \mathrm{C}$

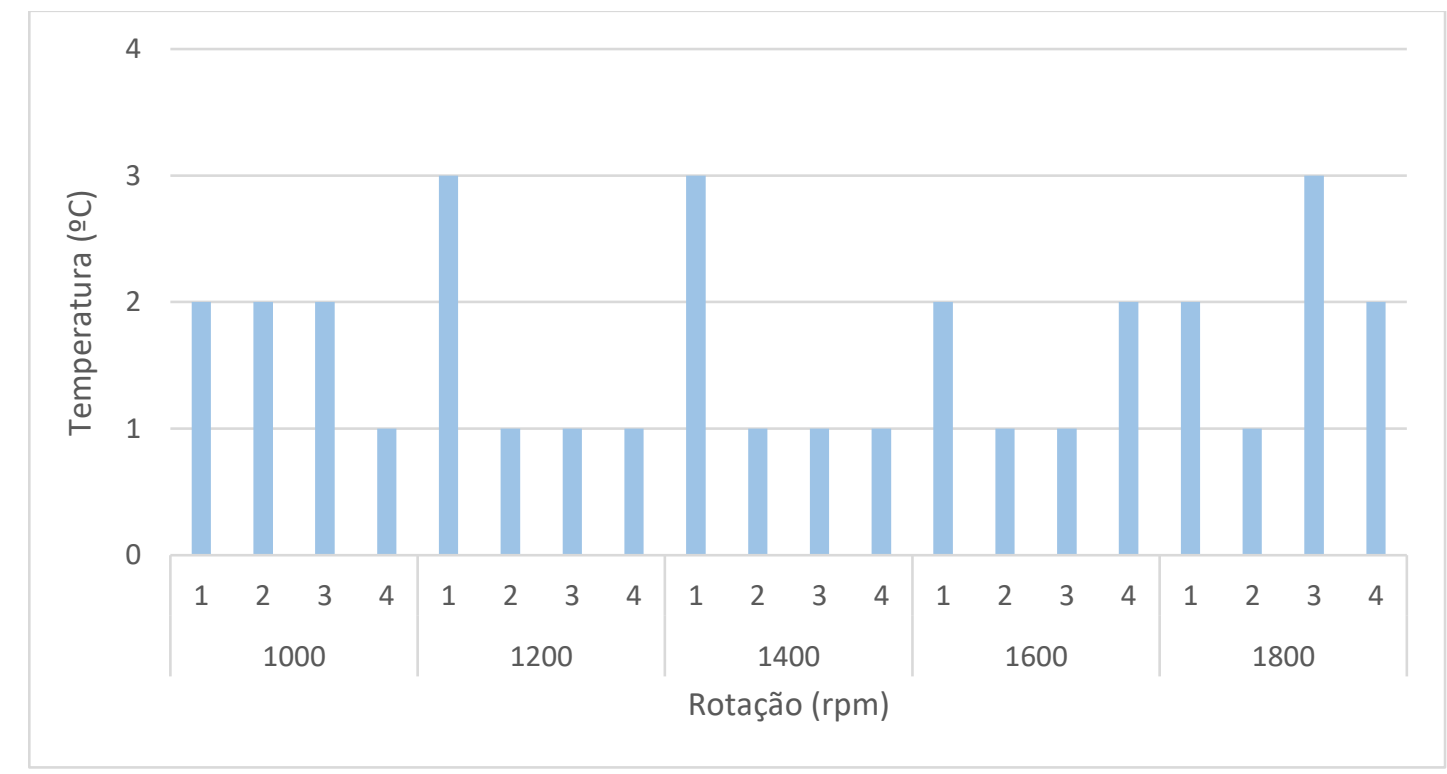

Fonte: Autores. 


\section{Conclusão}

Houve uma tendência para a faixa de temperatura de 110 a $130{ }^{\circ} \mathrm{C}$ e rotação abaixo de 1600 rpm apresentar maior porcentagem de proteína (32,86-35,90\%) e umidade (7,29-9,19\%) da torta de canola.

O extrato etéreo (E.E.) (24,59-32,66\%) e carboidrato (CARB) (21,48-27,29\%) da torta seguiram o mesmo comportamento, na qual, verificou-se alta porcentagem das mesmas, com baixas rotações (1400 rpm) independente das faixas de temperatura estabelecidas.

Para a fibra, as faixas de temperatura de $130-150{ }^{\circ} \mathrm{C}$ e rotação acima de $1600 \mathrm{rpm}$ apresentou maior quantidade de fibras na torta de canola. Os valores do teor de resíduo mineral fixo das amostras de torta, diminuem quanto menor for a rotação. O mesmo comportamento segue o rendimento do volume de extração do óleo, porém, o mesmo tem seu ponto ótimo nas temperaturas intermediários $\left(120-130^{\circ} \mathrm{C}\right.$ e $\left.130-140{ }^{\circ} \mathrm{C}\right)$.

Para umidade relativa do óleo de canola, a alta rotação teve efeito de conservar a maior umidade no óleo, independente das faixas de temperatura, ainda assim, não houve valores superiores a 9\%. Para as fibras, as faixas de temperatura de 130-150 ${ }^{\circ} \mathrm{C}$ e rotação acima de $1600 \mathrm{rpm}$, apresentou maior quantidade de fibras na torta de canola.

Em maiores faixas de temperatura e baixas rotações, a parte envoltória da semente foi degradada devido ao excesso de calor e pelo tempo de extrusão, tornando a cor da torta mais escura, diferentemente quando a rotação foi superior a 1600 rpm.

A menor quantidade de proteína, carboidrato e rendimento do volume de extração do óleo foi obtida, nas rotações e faixas de temperatura elevadas. As cores mais escuras da torta, referiram-se a alta porcentagem de proteína na torta de canola, e as cores mais claras, na alta porcentagem de extrato etéreo.

A metodologia estudada foi eficiente para a análise dos dados. Diante da complexidade das inúmeras análises e fatores de interação, a análise pelo delineamento fatorial completo também conhecida como coeficiente de resposta, com três repetições, foi suficiente para descrever o comportamento médios nas faixas de temperatura e rotação. A eficiência provou-se característica com as análises subsequentes, tanto pela quantidade de amostras, quanto pelas correlações estatísticas, tais como, o coeficiente de determinação.

A contribuição dos resultados para a área foi que com a compreensão dos rendimentos numéricos das variáveis estudadas foi possível programar e automatizar, na prensa extrusora, a qualidade esperada da torta e do, e, portanto, otimizandoa com aplicação de novas versões projetadas da máquina, para processo de extração mecânica de canola e outras culturas oleaginosas.

As perspectivas futuras seria a utilização da biomassa, ou seja, a torta de canola por meio do processo de extrusão para substituir as rações comercializadas, no setor da agropecuária. De forma que, o uso da prensa seja de fácil manejo e intuitiva para os usuários.

\section{Referências}

Araújo, K. (2014). The emerging field of energy transitions: Progress, challenges, and opportunities. Energy Research \& Social Science, 1, 112-121. doi: 10.1016/j.erss.2014.03.002

Araújo, B. L. O., Andrade, E. T., Nolasco, K. C. V., Castro, P. R., \& Castro Neto, P. (2020). Eficiência da extração mecânica de Moringa oleífera de acordo com diferentes condições de secagem de grãos review Research, Society and Development, 9(7), e937975133. doi: 10.33448/rsd-v9i7.5133

Abiove. (2019). Associação Brasileira das Indústrias de Óleos Vegetais. Soja e biodiesel no Brasil. São Paulo: Abiove. https://abiove.org.br/estatísticas/.

Barthet, V. J., \& Daun, J. K. (2011). Seed morphology, composition, and quality. In J. K. Daun, N. A. M. Eskin, \& D. Hickling (Ed.), Canola: Chemistry, Production, Processing, and Utilization (pp. 125-145). Urbana, USA: AOCS Press.

Bertol, T. M., \& Zanotto, D. L. (1997). Determinação do balanço de energia e nitrogênio de alguns alimentos para suínos. In Anais do Congresso Brasileiro de Veterinários Especialistas em Suínos, Foz do Iguaçu, PR.

Bueno, L. P., Lewandoski, C. F., Santos R. F., Reis L. S., Rodrigues, H. V., \& Batista, J. A. Automação 4.0 de prensa extrusora e aplicação energética de óleo de linhaça. Revista Técnico Científica do Crea-PR, 17, 1-11-11. 
Canola Council of Canada. (2011). Canola. Winnipeg: Canola Council of Canada. http://www.uscanola.com/site/filis/956/102394/ 365922/501107/Canola_LCA_data.pdf.

Conab. (2017). Companhia Nacional de Abastecimento. Acompanhamento da safra brasileira de grãos. Safra 2016/17, v. 4, n. 11. Brasília: Conab. 164p.

Mori, C., Tomm, G. O., \& Ferreira, P. E. P. (2014). Aspectos econômicos e conjunturais da cultura da canola no mundo e no Brasil. Passo Fundo: Embrapa Trigo. 36p.

Embrapa. (1991). Empresa Brasileira de Pesquisa Agrícola e Agropecuária. Tabela de composição química e valores energéticos de alimentos para suínos e aves. 3.ed. Concórdia: EMBRAPA/CNPSA. 97p.

Haeberlin, L., Nunes, C. F., Medeiros, E. P., Jaques, L. B. A., \& Paraginski, R. T. (2020). Comportamento fisiológico de sementes canola armazenadas em diferentes condições de teor de água e temperatura. Research, Society and Development, 9(7), e12973711. doi: 10.33448/rsd-v9i7.3711

Hoffmann, R., Kageyama, A. A. (1985). Modernização da agricultura e distribuição de renda no Brasil. Pesquisa e Planejamento Econômico, 15(1), 171-208.

Instituto Adolfo Lutz . (2008). Normas analíticas do Instituto Adolfo Lutz: métodos físico-químicos para análise de alimentos. São Paulo: IMESP. 1004p.

Milla, F., Rampim, L., Harmatiuka, P. H., Regiani, A. L. M., Muller, M. M. L., Faria, V. O., Pacheco, A. A., Olanik, C., \& Bini, P. E. C. (2020). Efeito do mecanismo sulcador e densidade de plantas na cultura da canola, na resistência a penetração e na cultura da soja subsequente. Research, Society and Development, 9(10), e6919108679. doi: 10.33448/rsd-v9i10.8679

Neves, C. I., Cenci. M. M., \& Rodrigues, M. T. (2016). Cassava processing wastewater as a platform for third generation biodiesel production. Scientia Agrícola, 73(5), 412-416. doi: 10.1590/0103-9016-2015-0302

Newkirk, R. (2011). Meal nutrient composition. In J. K. Daun, N. A. M. Eskin, \& D. Hickling (Ed.), Canola: Chemistry, Production, Processing, and Utilization (pp. 229-244). Urbana, USA: AOCS Press

Panizzon J., Cenci, M. M., Grabowski G., \& Jahno D. V. (2020). Perdas e desperdícios de alimentos: Reflexões sobre o atual cenário brasileiro Brazilian Journal of Food Technology, 23, e2019134. doi: 10.1590/1981-6723.13419

Pighinelli, A. L. M. T. (2010). Estudo da extração mecânica e da transesterificação etílica de óleos vegetais (Tese de Doutorado). Engenharia Agrícola, Universidade Estadual de Campinas, Campinas-SP.

Rivas, C. O. R., \& Bautista, R. O. (2003). La colza/canola, una oleaginosa para explotarse en nuestro país. Revista Claridades Agropecuarias, 115, 3-18. http://www.infoaserca.gob.mx/claridades/ revistas/115/ca115.pdf\#page=3.

Rigon, C.A.G., Goergen, A.B., Bordin, R., Pilla, R.B., Zanatta, T.P., Silva, V.R., \& Tomm, G.O. (2017). Características agronômicas, rendimento de óleo e proteína de canola em diferentes épocas de semeadura. Revista Brasileira de Tecnologia Agropecuária, 1(2), 124-132

Sarwar Gilani, G., Wu Xiao, C, \& Cockell, K. A. (2012). Impact of anti-nutritional factors in food proteins on the digestibility of protein and the bioavailability of amino acids and on protein quality. British Journal of Nutrition, 108(S2), S315-S332. doi: 10.1017/S0007114512002371

Scapinello, C., Furlan, A. C., Moreira, I., \& Murakami, A. E. (1996). Valor nutritivo do farelo e da semente de canola para coelhos em crescimento. Revista da Sociedade Brasileira de Zootecnia, 25(6), 1115-1123

Tomm, G. O. (2005). Situação em 2005 e perspectivas da cultura de canola no Brasil e em países vizinhos. Passo Fundo: Embrapa Trigo. 21p. http://www.cnpt.embrap.br/biblio/bp/p_bp26.htm.

Tomm, G. O., Wiethölter, S., Dalmago, G. A., \& Santos, H. P. (2009). Tecnologia para produção de Canola no Rio Grande do Sul. Passo Fundo: Embrapa Trigo. 41p. http://www.cnpt.embrapa.br/biblio/dop_do113.htm.

Ulian, G., Lima I. C., \& Lemos M. M. C. (2017). Water management assessment methodology for urban planning. Revista Ambiental Água, 12(1), 33-46. doi: 10.4136/ambi-água.1917

Vieira, H. B., Buschinelli, C., Ramos, N. P., Tomm, G.O., Fontes, L. P., \& Rodrigues, I. A. (2010). Gestão ambiental em propriedade rural dedicado a Produção de canola para geração de biodiesel na região de passo fundo (RS). In Anais do $5^{\circ}$ Congresso Internacional de Bioenergia, Curitiba, PR.

Yacu, W. (1990). Process Instrumentation and control in food extruders. Cereal Foods World, 35(9), 919-926. 